\title{
Article
}

\section{Curly Questions}

\author{
Sarah E. Medland \\ Psychiatric Genetics, QIMR Berghofer Medical Research Institute, Brisbane, Australia
}

\begin{abstract}
This letter reflects on my collaborations with Nick Martin over the past 18 years. Working together we have applied twin-family and statistical genetics methods to examine the genetic architecture and identify genetic variants influencing a range of physical, psychological and social traits. The common thread across much of this work has been the empirical questions: Why are we the way we are and how can this knowledge help us when things go wrong?
\end{abstract}

Keywords: GWAS; collaboration; reflections

(Received 24 February 2020; accepted 7 April 2020)

I have had the great pleasure of working with Nick in one way or another since 2002. Over the years Nick has worked on almost everything, and at one stage Lon Cardon actually worked out the multiple testing burden of GWAS for everything with the aim of tackling Nick with this at the conclusion of one of his ra-ra talks at Boulder. While much of this work has important implications for health and wellbeing, some is less serious in nature.

One particularly memorable project focused on the genetics of hair curl and resulted in a genomewide association study (GWAS) published in the American Journal of Human Genetics in 2009 (Medland et al., 2009). This paper was actually designed to be a baseline paper in which we could report the details of the quality controls and imputation of our GWAS data for almost 5000 individuals that had been accumulated over seven waves of singlenucleotide polymorphism (SNP)-based genotyping. Despite this, with the usual GenEpi style, we decided that the GWAS needed to use all the information available in our data that had been collected on a three-point scale and use data from all available individuals, which meant that we needed to model relatedness. This, of course, meant that the GWAS had to be run in (classic) Mx. After a great deal of work extracting the SNP data, merging it with phenotypes, running the GWAS in the context of an AE model and outputting the results was streamlined down to $\sim 30 \mathrm{~s}$ per SNP. Thankfully, this work predated the 1000 Genomes Project so GWAS in the three cohorts for 2.4 million SNPs only used $\sim 60,000 \mathrm{CPU}$ hours. Our major finding was an association with the 1q21 region, which included a coding, nonsynonymous variant located in the third exon of $\mathrm{TCHH}$. The variant was only

Author for correspondence: Sarah Medland, Email: Sarah. Medland@qimrberghofer. edu.au

Cite this article: Medland SE. (2020) Curly Questions. Twin Research and Human Genetics 23: 98-99, https://doi.org/10.1017/thg.2020.23 seen in European populations and was associated with straighter hair, explaining around $6 \%$ of the variance in hair shape. While we were pretty happy about this, we were under no illusions as how important this finding was in the greater scheme of things, which made what happened next even more surprising.

About a month after the paper was published, Nick was emailed a couple of questions by a UK-based journalist. As it turns out the key question in that email was: I also wondered if you could tell me what sort of application this discovery could have in future? Might it be possible to influence the curliness of hair by different means? Could there be an alternative to heated hair straighteners? A follow-up email pressed on: Could you develop new 'treatments' (like a pill?) which would make hair curlier or straighter, rather than treating the hair directly? To which the reply which was sent was Potentially, yes.

We were somewhat unprepared for the deluge of media attention that descended on us a few days later when the UK Daily Telegraph announced to the world that we had developed a pill to straighten hair. Arriving at work the next morning, we dodged TV crews for three different stations and tried to explain what had happened to the QIMR media team - the local journalists were irate that we had not given the breaking story to a local media outlet. It was unfortunately a slow news week and thanks to the view and lift model of journalism the story spread. As shown in Figure 1, even now, 10 years later, a Google search for 'Nick Martin' curly hair pill yields $\sim 10,500$ hits, and the interest from both media and individuals has never gone away. Over the last 10 years, we have had queries from a range of companies. Ironically, this is the only GWAS finding that we did actually meet with business development with about patenting; however, the advice was it wasn't worth it.

Of course, the grass is always greener on the other side, so in European countries this magical pill was apparently able to curl hair which in other places the pill straightened hair.

Across the years, my favorite query about this work came in the form of a physical letter from Brazil, which arrived with six stamps 
Fig. 1. A Google trends search for curly hair pill.

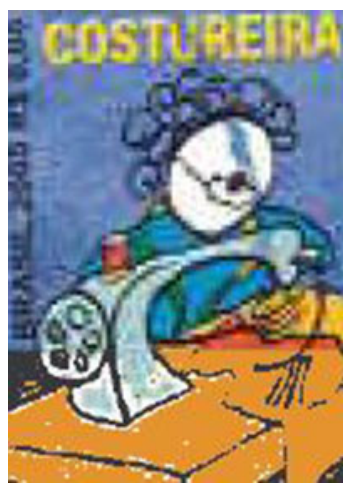

Fig. 2. Brazilian stamp.
December 2010

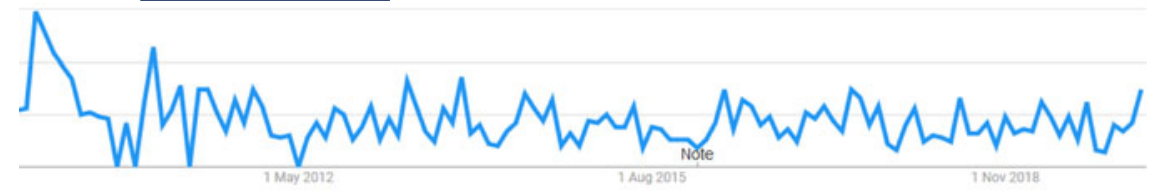

on it (one of which most appropriately showed a very curly haired Costureira; see Figure 2). The letter was written in 20-pt font (mostly in caps) which included the very memorable line 'I AM A DEALER IN BRAZIL', a request for exclusivity and an intriguing question about whether the pills were for ETERNAL use.

Obviously, we missed a trick on this one, Nick. Just think if what the funding line would have looked like had we actually tried to make a pill to straighten hair...

\section{Reference}

Medland, S. E., Nyholt, D. R., Painter, J. N., McEvoy, B. P., McRae, A. F., Zhu, G., Martin, N. G. (2009). Common variants in the trichohyalin gene are associated with straight hair in Europeans. American Journal of Human Genetics, 85, 750-755. doi: 10.1016/j.ajhg.2009.10.009 